\title{
Post Marketing Surveillance Requirements of Drug Eluting Stents in India and European Union
}

Swathilakshmi $\mathbf{U}^{1^{*}}$, Shailaja $\mathbf{P}^{1}$, Ratna $\mathbf{V}^{1}$, Prasanth $\mathbf{S}^{2}$ and Daniel BA ${ }^{2}$

${ }^{1}$ Deparmtent of Pharmaceutical Science, Andhra University, Visakhapatnam, Andhra Pradesh, India

${ }^{2}$ S3V Vascular Technologies Pvt Ltd, Bangalore, Karnataka, India

"Corresponding author: Swathilakshmi U, Department of Pharmaceutical Science, Andhra University, Visakhapatnam, Andhra Pradesh, India, Tel: 089128 44000; Email: uswathilakshmi@gmail.com

Received date: July 26, 2017; Accepted date: August 28, 2017; Publish date: September 06, 2017

Copyright: (c) 2017 Swathilakshmi U, et al. This is an open-access article distributed under the terms of the Creative Commons Attribution License, which permits unrestricted use, distribution, and reproduction in any medium, provided the original author and source are credited.

\begin{abstract}
The objective of present review is to offer an overview of post marketing surveillance of drug eluting stents in India and European Union (EU). The drug eluting stents are used for the treatment of coronary angioplasty Drug eluting stents can significantly reduce the rate of restenosis by $60-75 \%$ as compare to bare metal stents. New technologies are often introduced into the market without proper safety and effectiveness data. To know about the safety and effectiveness of the drug eluting stents after marketing, Post marketing surveillance plays a vital role it includes Periodic Safety Update Report (PSUR) and Post Marketing Clinical Follow Up Studies (PMCF) for the identification of residual risk during the process and also explained about the functions of manufacturer and notified bodies, regulatory requirements of drug eluting stents in India and European market.
\end{abstract}

Keywords: Drug eluting stent; Post market surveillance; Periodic safety update report; India; European Union (EU); Residual risk

\section{Introduction}

Drug eluting stents are used for the treatment of arteriosclerosis which is used to remove the cholesterol deposited on the artery wall and prevent the carcinogenicity by releasing anti proliferative drugs. To address this problem, drug-eluting stents are place in the artery, preventing it from narrowing or clogging [1]. Thus, drug-eluting stents eliminate the need for repeated revascularization procedures that are used to treat restenosis (narrowing of blood vessels). Restenosis caused by various reasons at the same time solution for the restenosis is also complex method. Traditional bare-metal stents have restenosis rates of up to 25\%; current 2nd and 3rd generation drug-eluting stents have reduced that rate to single digits. The Smithers apex reports details the product technology characteristics and description of product used for the atherosclerosis, the products including coronary catheters and various types of stents (Figures 1 and 2) [2].

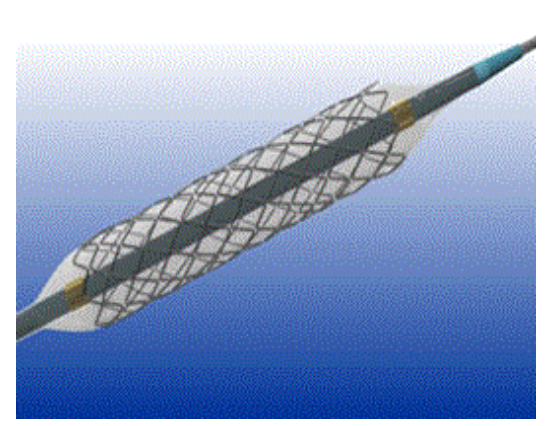

Figure 1: Drug eluting stent.

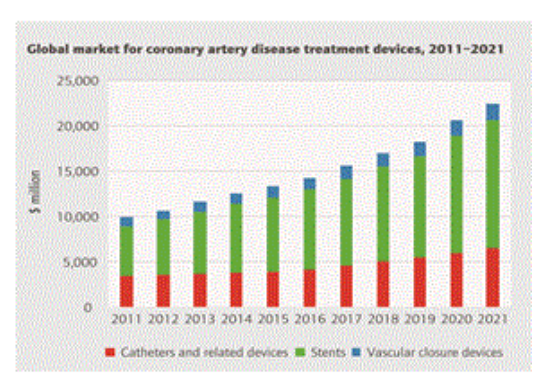

Figure 2: Global market of drug eluting stents.

Post marketing surveillance is the part of the Phase IV clinical trials It refers to the monitoring the safety of devices once they reach the market after clinical trials. It evaluates devices taken by individuals under a wide range of circumstances over a longer period of time. Such surveillance is much more likely to detect previously unrecognized positive or negative effects that may be associated with a device. The majority of Post marketing surveillance concern adverse reactions of device monitoring and evaluation. Other important Post marketing surveillance components include unapproved or off-label use of device. The documentations of adverse events associated with the medical devices are possible through post marketing surveillance plan [3]. Hence in the post marketing surveillance plan there is no inclusion and exclusion criteria involved it can be worked on unanswered questions during clinical trials. Post marketing surveillance studies are very well adapted to answer questions about quality safety benefits and treatments cost and tolerance of patients can be explained. Current information from the nationwide data obtained from the Eudravigilance programme of medical device in European Union and Metriovigillance programme of medical device from India clime-made data base and databases/registries. Each of these approaches has their 
own advantages and loopholes for providing in depth knowledge into different aspects of real world performance and usage of device. When these systems are evaluated, it is useful to consider the number of patients included and the details of data include adverse events and incidents associated with device and user errors are collected [4].

The objective of present review is to provide overview on Post marketing surveillance requirements of drug eluting stents in India and EU market including regulatory requirements and post marketing surveillance requirements i.e., Periodic safety update report and Post market clinical follow up studies and clinical investigation of drug eluting stents in European Union and India. The European medical device directive and the Central Licensing Approval Authority branch of CDSCO may be used as basis for the future studies on regulations and requirements of post marketing surveillance data of drug eluting stents.

\section{Regulatory Requirements of PMS}

All regulatory systems recognize that adverse event reporting alone cannot capture all risks related to the use of medical devices. Medical devices long-term implantable devices and devices for home use are examples of cases where the evaluation of the performance from adverse event reports alone is difficult or even impossible. For this reason, the world global regulatory authorities conduct various programmes for the reporting of adverse events and incidents associated with the devices. In India "Surveillance means practice of monitoring the safety of medical devices [5].

The word "Market Surveillance" is tasks performed by the regulatory authorities. While "Post market Surveillance" Refer to the activities carried out by the manufacturers. Corrective actions and preventive actions are carried out by the manufacturer to reduce the risk associated with the medical devices European Union New Medical Device regulations which are released on 26 may 2017, Meddev2.12-1 Rev8 "Guidelines On A Medical Devices Vigilance System" MEDDEV 2.12-2 Rev2 "Post-Market Clinical Follow-Up (PMCF) studies" and in India the Central Licensing Approval Authority (CLAA) monitors.

\begin{tabular}{|c|c|}
\hline India & EU \\
\hline $\begin{array}{l}\text { The regulatory bodies like CLAA (Central } \\
\text { licensing approval authority) the branch of } \\
\text { CDSCO adopt the guidelines from BIS and } \\
\text { ISO and monitor the post marketing } \\
\text { surveillance data of medical devices }\end{array}$ & $\begin{array}{l}\text { EU the post marketing } \\
\text { surveillance data is monitored } \\
\text { by EUDAMED, CMdh and EMA }\end{array}$ \\
\hline $\begin{array}{l}\text { Sree Chitra Tirenal Institute for Medical } \\
\text { Sciences and Technology (SCTIMST) for } \\
\text { adverse event reports monitoring }\end{array}$ & $\begin{array}{l}\text { MEDDEV2.12-1 Rev8 } \\
\text { "guidelines on a medical } \\
\text { devices vigilance system" }\end{array}$ \\
\hline \multirow[t]{2}{*}{$\begin{array}{l}\text { National coordination centre-Materiovigilance } \\
\text { programme of India }\end{array}$} & $\begin{array}{l}\text { MEDDEV2.12-2 Rev2 "post- } \\
\text { market clinical follow-up } \\
\text { (PMCF) studies" }\end{array}$ \\
\hline & $\begin{array}{l}\text { Periodic safety updates report } \\
\text { respiratory is also one of } \\
\text { regulatory body for the post } \\
\text { marketing surveillance }\end{array}$ \\
\hline
\end{tabular}

Table 1: Regulatory bodies for post market surveillance in INDIA and EU.

The Post marketing surveillance of medical devices and National Collaborating centre-MateroVigilance Programme of India, collaborates with Sree Chitra Tirunal Institute for Medical Sciences and
Technology (SCTIMST) for adverse event reports monitoring, National coordination center-MateroVigilance programme of India includes Indian pharmacopeia commission, technical support and resource center-Materio vigilance programme of India includes National Health System Resource Centre (NHSRC)are carried out the post marketing surveillance of medical devices (Table 1) [6].

\section{Post Marketing Surveillance Requirements of Drug Eluting Stents}

Manufacturer of class IIa IIb, III medical devices should prepare the periodic safety update report and submit to the competent authority for notifying about the adverse events associated with the above classes of medical devices, implemented risk management plans, and the post marketing clinical follow up data for the class III medical devices is essential element of the conformity assessment to demonstrate the essential requirements of the drug eluting stents. Manufacturer of class III devices and implantable devices reports shall be submitted by means of electronic system to the NB'S involved in the conformity assessment.

The Notified bodies shall review the report and shall add its evaluation to the database with details of any action taken such reports and the notified body evaluation shall be available to competent authorities through the electronic system (Table 2) $[7,8]$.

\begin{tabular}{|c|c|c|c|}
\hline $\begin{array}{l}\text { S. } \\
\text { No. }\end{array}$ & Parameters & India & EU \\
\hline 1 & Definition & $\begin{array}{l}\text { Practice of monitoring } \\
\text { safety }\end{array}$ & $\begin{array}{l}\text { Active collection of } \\
\text { information on safety }\end{array}$ \\
\hline 2 & Regulation & $\begin{array}{l}\text { CLAA branch of CDSCO } \\
\text { (BIS, ISO) }\end{array}$ & $\begin{array}{l}\text { EMEA (CMdh. PSUR } \\
\text { respiratory) }\end{array}$ \\
\hline 3 & Requirements & $\mathrm{PMCl}, \mathrm{PSUR}$ & PMCF, PSUR \\
\hline 4 & What to report & $\begin{array}{l}\text { Adverse events associated } \\
\text { with device }\end{array}$ & $\begin{array}{l}\text { Trend reports, incident } \\
\text { report, user error, } \\
\text { adverse events }\end{array}$ \\
\hline 5 & $\begin{array}{l}\text { Whom to } \\
\text { report }\end{array}$ & DCGI, SCTIMST & $\begin{array}{l}\text { PSUR Respiratory, } \\
\text { CMdh, forwarded to } \\
\text { EMEA }\end{array}$ \\
\hline 6 & How to report & $\begin{array}{l}\text { Through e-submission gate } \\
\text { way }\end{array}$ & e-submission, web client \\
\hline 7 & Format & - & $\begin{array}{l}\text { Xml zip file (data should } \\
>10 \mathrm{Mb} \text { ) }\end{array}$ \\
\hline 8 & $\begin{array}{l}\text { Who can } \\
\text { report }\end{array}$ & $\begin{array}{lr}\text { Manufacturer } & \text { physician, } \\
\text { Pharmacist, } & \text { Nurses, } \\
\text { Common People } & \end{array}$ & $\begin{array}{l}\text { Manufacturer, Physician, } \\
\text { Nurses, General Public }\end{array}$ \\
\hline 9 & $\begin{array}{l}\text { Time scale for } \\
\text { reporting } \\
\text { incidents }\end{array}$ & $\begin{array}{l}30 \text { days from the first } \\
\text { marketing approval, if } \\
\text { suspected unexpected } \\
\text { adverse events } 15 \text { days } \\
\text { from incident occur date }\end{array}$ & $\begin{array}{l}\text { Serious public health } \\
\text { threat } 2 \text { days Death or } \\
\text { Unanticipated serious } \\
\text { deterioration in state of } \\
\text { health } 10 \text { days, Others } \\
30 \text { days }\end{array}$ \\
\hline 10 & $\begin{array}{l}\text { PSUR } \\
\text { submission } \\
\text { intervals }\end{array}$ & $\begin{array}{l}\text { Every } 6 \text { months for first two } \\
\text { years and annually for next } \\
\text { two years }\end{array}$ & $\begin{array}{l}\text { Every } 6 \text { months for first } \\
\text { two years and annually } \\
\text { for next three years }\end{array}$ \\
\hline
\end{tabular}

Table 2: Post market surveillance requirements for DES in India and EU. 


\section{Post Marketing Clinical Follow Up Studies of Drug Eluting Stents in European Union}

While clinical evidence is an essential element of the premarket conformity assessment process to demonstrate the conformity to essential requirements. Post marketing clinical follow up is mainly useful for the pre-market clinical data reveal any unanswered questions about safety or effectiveness, adverse events that warrant further investigation, if premarket clinical data improperly generalised and the lifespan of the device extended beyond the time frame that premarket clinical data, new information emerged that affects premarket data, extended population that were not included in clinical trials. It is important to recognise that there may be limitations to the clinical data available in the pre-market phase. Such limitations may be due to the number of subjects and investigators involved in an investigation, the number of subjects and investigators or the controlled setting of the clinical investigation versus the full range of clinical conditions encountered in general medical practice. The favourable benefit risk ratio can be demonstrated by post marketing clinical follow up studies. As part of the manufacturer quality management system the identification of residual risk need appropriate post marketing surveillance plan the ISO 14971 is the international standard for the identification of residual risk associated with the medical devices. The residual risk should be investigated and assessed in the post market phase through systematic post market clinical follow-up studies post marketing clinical follow up is part of the clinical investigation, clinical investigation is the part of post marketing surveillance for the critical examination of the risk associated with the devices. Clinical data obtained from the post marketing surveillance that include post marketing clinical follow up studies by the manufacturer are not intended to replace the data obtained from the premarket clinical trials necessary to demonstrate conformity with the provision of the regulations. However After placing the medical device on the market there is a difficulty to gather information. Post marketing clinical investigation is the study other than surveillance performed after marketing approval has been given to the device required by the Central Licensing Authority for optimizing the intended use of the medical device. Post Marketing Clinical investigation includes, The quality of the medical devices which was monitor under ISO 13485, Additional drug device interaction, Safety studies, Investigation designed to support use under the approved indication for the identification of mortality and morbidity of the medical devices especially drug eluting stents. It required when residual risk of a medical device that is used properly according to labeling. Long-term performance and impact of the medical device affected by new materials or technologies are used. Events that is specific to defined population groups. The medical device Performance is a more representative of the populations like pregnant and nursing women, paediatrics. New indication for use or claim has been approved. Significantly, changes have been made to the medical device (or) labeling [9-11].

\section{Periodic Safety Update Reports of Drug Eluting Stents}

Manufacturer of the class IIb and III and class C and D devices should submit the periodic safety update report throughout the lifetime of the device to PSUR respiratory in European Union and CLAA in India. Manufacturer of class IIa, IIb, and class III and Class C and $\mathrm{D}$ devices submit the periodic safety update report at least annually and for two years and later two years from the next submission. The regulatory authorities some time may increases the submission period more than five years based on the public health interest [12].

\section{Format and Contents of Periodic Safety Update Report Includes as Follows in EU}

The PSUR shall be based on all available data and shall focus on new information, which has emerged since the data lock point of the last Periodic safety update report, cumulative performance of device taken into consideration for the assessment of safety and benefit risk ration. The safety efficacy and effectiveness data used for the preparation of Periodic safety update report obtained from the non-clinical intervention, spontaneous reports, active surveillance, investigational product quality, observational studies and data usage and utilization of product, patients observation and clinical trials. The Periodic safety update report contains title page including signature of the manufacturer and contact information. Executive summary brief description about the device, followed by the table of content of the document.

Introduction of the device, therapeutic action and duration of effect and risk class of the device and intended use should be mentioned and worldwide market authorisation statues if there is any withdraw or recall of product from the market, and actions taken in the reporting intervals regarding safety and performance of the device, estimated exposure of the population for the clinical trials cumulative interval of clinical trials should mention clearly and data tabulation should be maintained. reference information which was obtained from the literature survey and serious adverse events from the clinical trials and interval summary tabulation from post marketing data sources, demonstrates about the adverse events should be maintained and summarizes the significant data obtained from the clinical trials (i.e., completed, ongoing, long term follow up and other the therapeutic used of medical device) and new safety data related to the drug-device or device-device, device-polymer combinations. summarizes the data regarding signal and risk evaluation and benefit risk evaluation, integrated benefit risk evaluation for the authorised indication should clear mentioned about the conclusions drawn from the post marketing data and appendices of Periodic safety update report if any [13].

\section{Format and Content of Periodic Safety Update Reporting India}

Subsequent to approval of an Investigational medical device, it shall be closely monitored for their clinical safety once they are marketed. The applicants shall furnish Periodic safety update report in order to the report all the relevant new information from the appropriate sources related to safety and indicates whether changes will be made to product information in order to optimize the use of the product. One medical device should be covered under the one Periodic safety update report. Both clinical and non-clinical data are published under single Periodic safety update report. The Periodic safety update report should submit for six months for first two years and annually for next two years. The duration Periodic safety update report may extend based on the public interest and severity of adverse events associated with devices [13].

The Title Page of Periodic safety update report contains the signature and address of the manufacturer, and followed by the introduction about the device, risk based classification, intended use and therapeutic effect, Current worldwide marketing authorization status of medical device should be mentioned and withdrawal of the 
device from the any world market or recall of device from the world market should be mentioned, estimated patients exposure under clinical trials and the reference information obtained from the literature survey and customer feedback should Cleary mentioned in the document, overall safety information and adverse events associated with the device can be mentioned. Conclusions drawn from the studies are mentioned followed by the appendix of the document (Table 3).

\begin{tabular}{|c|c|c|c|}
\hline Individual incident reporting & \multicolumn{2}{|l|}{ Periodic summary reports } & $\begin{array}{l}\text { Report at the time the adverse trend is } \\
\text { identifies }\end{array}$ \\
\hline \multirow{4}{*}{$\begin{array}{l}\text { Clinical/Symptomatic Death that } \\
\text { is probably or possibly device } \\
\text { related MI or heart failure that is } \\
\text { probably or possibly device } \\
\text { related Acute coronary arterial } \\
\text { perforation/dissection leading to } \\
\text { haemopericardium/pericardial } \\
\text { Cardiogenic shock }\end{array}$} & Clinical & Periodicity & \multirow{4}{*}{$\begin{array}{l}\text { All reportable adverse incidents Clinical/ } \\
\text { Symptomatic Side branch occlusion Distal emboli } \\
\text { (tissue, thrombotic/thrombus, plaque)Acute } \\
\text { peripheral artery injury/perforation/dissection Non- } \\
\text { fatal bleeding complications (e.g. hemorrhage), } \\
\text { which may require transfusion Infection-local } \\
\text { and/or systemic Peripheral vascular or nerve injury }\end{array}$} \\
\hline & $\begin{array}{l}\text { Adverse reaction associated with the stent material } \\
\text { (including, drug or polymer carrier) and/or delivery system } \\
\text { materials }\end{array}$ & 12 Monthly & \\
\hline & $\begin{array}{l}\text { Stent/target vessel thrombosis (Thrombotic occlusion/ } \\
\text { embolism), In-stent re-stenosis, target vessel or lesion } \\
\text { revascularization }\end{array}$ & 3 Monthly & \\
\hline & $\begin{array}{l}\text { All CVA (Stroke and TIA) within } 12 \text { months of PCI } \\
\text { procedure. Listing acute, sub-acute and late strokes } \\
\text { separately. This should be separated out by ischemic } \\
\text { stroke. }\end{array}$ & 3 Monthly & \\
\hline
\end{tabular}

Table 3: What should be reported in PSUR of drug eluting stents?

\section{For Manufacturers in EU and India}

The manufacturer of the class IIa, IIb, and Class III and class C and $\mathrm{D}$ devices or authorised representative of the manufacturer shall notify the relevant competent authority about the incidents associated with the medical devices and field safety corrective actions taken by the manufacturer. The manufacturer should ensure that their authorised representative within the European union and India, persons responsible for placing devices on the market and any other agents authorised to act on their behalf for purposes relating to medical devices vigilance, are kept informed of incident reports as appropriate. Where an incident occurs as a consequence of the combined use of two or more separate devices (and/or accessories) made by different manufacturers, each manufacturer should submit a report to the relevant national competent authority. Manufacturer of the class IIa, IIb, III Devices should follow the notified bodies instructions for the developments of post marketing surveillance plan [13].

\section{The Role of the Notified Bodies in EU}

Even though the Notified Bodies do not play a key operational role in the Medical Device Vigilance System, the overall performance of the Medical Device Vigilance System is supported by the Notified Body activity in the following areas are Assessment of vigilance procedures, Audit of the implementation of the vigilance procedures, and link with other systems e.g. Corrective and Preventive Action (CAPA), FSCA Assessment of the impact of vigilance issues on the certification granted Liaise with the National Competent Authority if required, e.g. specific investigations/audits based on a request of the National Competent Authority. Further guidance on these areas is provided by Notified Bodies Operation Group documents or Notified Body recommendations [13].

\section{Conclusion}

Understanding the Post marketing surveillance requirements of drug eluting stents in Indian and European market and also explained about duties of manufacturer and regulatory bodies during Drug Eluting Stents post marketing surveillance. Mainly highlighted the periodic safety update report of manufacturer in India and EU and residual risk identification by using post marketing clinical follow up studies in EU and their regulatory requirements.

\section{References}

1. www.emergogroup.com/services/europe

2. www.smithersapex.com

3. Sousa JE, Costa MA, Abizaid A, Abizaid AS, Feres F, et al. (2001) Lack of neointimal proliferation after implantation of sirolimus-coated stents in human coronary arteries: a quantitative coronary angiography and threedimensional intravascular ultrasound study. Circulation 103: 192-195.

4. Morice MC, Serruys PW, Sousa E, Fajadet J, Hayashi E, et al (2002) A randomized comparison of a sirolimus-eluting stent with a standard stent for coronary revascularization. N Engl J Med 346: 1773-1780.

5. Moses JW, Leon MB, Popma JJ, Fitzgerald PJ, Holmes DR, et al. (2003) Sirolimus-eluting stents versus standard stents in patients with stenosis in a native coronary artery. N Engl J Med 349: 1315-1323.

6. Regulation of the European Parliament and of the Council (2016) Council of the European Union.

7. Guidelines on a Medical Devices Vigilance System (2013) European Commission.

8. Drugs and Cosmetics Act (2017) Ministry of health and family welfare.

9. Directive 2007/47/Ec of The European Parliament and of The Council (2007) J Europ Union.

10. Guidance on the Vigilance System for CE-Marked Medical Devices (2015) DSVG02 Coronary Stents Medical Devices: Guidance Document.

11. Review of Current Requirements on Post-market Surveillance (2005) Global Harmonization Task Force.

12. Evaluation of Clinical Data: A Guide for Manufacturers and Notified Bodies (2008) European Commission.

13. Guidelines on Clinical Investigation: A Guide for Manufacturers and Notified Bodies (2010) European Commission Directorate General for Health and Consumers. 